УДК: 005.95/.96

JEL: H11

Н. Д. Стрекалова ${ }^{1}$ Г. И. Рогова ${ }^{2}$

СОЦИАЛЬНЫЕ АСПЕКТЫ УПРАВЛЕНИЯ

ПРОФЕССИОНАЛЬНЫМ РАЗВИТИЕМ

ГОСУДАРСТВЕННЫХ СЛУЖАЩИХ ФЕДЕРАЛЬНОЙ

НАЛОГОВОЙ СЛУЖБЫ РОССИИ:

РЕЗУЛЬТАТЫ ЭМПИРИЧЕСКОГО ИССЛЕДОВАНИЯ

${ }^{1}$ Национальный исследовательский университет «Высшая школа экономики»,

Российская Федерация, 194100, Санкт-Петербург, ул. Кантемировская, 3

${ }^{2}$ Нижегородский институт управления - филиал Российской академии народного хозяйства и государственной службы при Президенте Российской Федерации, Российская Федерация, 603950, Нижний Новгород, пр. Гагарина, 46

В статье рассматривается проблема профессионального развития государственных гражданских служащих. Показано, что профессионализм государственных служащих формируется под влиянием их профессиональных установок, мотивации в профессиональных достижениях. Выявлены структура, основные типы профессиональных установок руководителей - начальников налоговых инспекций Федеральной налоговой службы России. Представлены результаты гендерного анализа профессиональных установок руководителей. Даны рекомендации по использованию полученных результатов в практике работы кадровых служб ФНС России.

Ключевые слова: профессионализм, профессиональное развитие, управление профессиональным развитием, мотивация профессионального развития, профессиональные установки, Федеральная налоговая служба России.

\title{
SOCIAL ASPECTS OF PROFESSIONAL DEVELOPMENT MANAGEMENT OF RUSSIAN FEDERAL TAX SERVICE CIVIL SERVANTS: RESULTS OF EMPIRICAL RESEARCH
}

N.D. Strekalova ${ }^{1}$, G. I. Rogova ${ }^{2}$

${ }^{1}$ National Research University Higher School of Economics,

3, ul. Kantemirovskaya, Saint-Petersburg, 194100, Russian Federation

${ }^{2}$ Nizhny Novgorod institute of public and business administration - a branch of Russian

Presidential Academy of National Economy and Public Administration, 46, pr. Gagarina, Nizhny

Novgorod, 603950, Russian Federation

This article focuses on professionalism and professional development of public service employees (civil ones). The goal of the study was to examine professional motivation of these employees and to carry out an empirical study of professional attitudes of Federal Tax Service (FTS) executives in the Russian Federation. Sociological approach (based on management sociology) and concepts of new public management, public service motivation and achievement motivation were used in the study. It is shown that professionalism of the employees is formed by virtue of their professional attitudes and professional achievements motivation. It is emphasized in management, that it is necessary to find out and take into consideration professional attitudes

(C) Санкт-Петербургский государственный университет, 2016 
defining an employee's willingness to professional development, and efforts he/she applies. The study reveals the structure and main types of professional attitudes of managers - Federal Tax Service executives in Russia. The results of gender analysis of the professional attitudes of the managers are presented as well.

The formal survey method (Work Test) was used to identify professional attitudes of the heads of tax offices. The survey involved 90 heads of tax offices from different regions of Russia. It was found out that the dominating attitudes in the structure of professional attitudes of the heads of tax offices are those aimed at professional and qualification development and creative type of work. The dominating type of the executives surveyed is that of "experts-creators", which means a strong focus on professional development, creative type of work, as well as internal work motivation. The research did not confirm the hypothesis that the attitudes of the career growth and algorithmic type of work (doers) dominate in the structure of professional attitudes of the tax office executives. The gender analysis of the data obtained showed that female executives dominate among tax offices executives. Selective data do not give grounds to reject the hypothesis that female heads are more focused on professional and qualification development and creative type of work than male ones; however, this dependence is not of any significance. Recommendations of how to implement the obtained results for human resource professionals of the Federal Tax Service in Russia are offered. The study contributes to the development of new public management, public service motivation, (issues of public service employees' professional development motivation and management), as well as to the testing of the method of finding out professional attitudes of the employees indicated. The study is of practical significance for strategic planning and management of public service employees' professional development and implementation of the Concept of Personnel Policy of the Federal Tax Service of the Russian Federation.

Keywords: professionalism, professional development, professional development management, professional development motivation, professional attitudes, Federal Tax Service of Russia.

\section{ВВЕДЕНИЕ}

Масштабы и сложность задач, стоящих перед современным российским обществом и его государственными институтами в условиях динамичных социально-экономических изменений, обостряют актуальность и повышают практическую значимость профессионального развития государственных гражданских служащих. Результативность и эффективность деятельности Федеральной налоговой службы России (ФНС РФ) как органа государственного управления в значительной степени зависит от профессионализма госслужащих - ее руководителей и специалистов. Актуальность решения этой задачи государственной важности подчеркивается в Концепции кадровой политики [Об утверждении Концепции..., 2015] и в приказах ФНС РФ [О создании Совета ФНС России..., 2015].

Стремительные темпы глобализации экономики, развития новых технологий за последние два десятилетия привели к глубоким изменениям в методах ведения бизнеса. Одновременно происходят значительные трансформации в подходах к государственному управлению. Идет реформирование ФНС РФ как социального института. Новые реалии социально-экономической и нормативно-правовой среды стали причиной динамичных изменений в российском налоговом 
законодательстве, усиления контроля за соблюдением налогового законодательства и требований к отчетности.

Для выполнения своих функциональных обязанностей сегодня госслужащим налоговых органов необходимы аналитические навыки, творческие способности: умение решать нестандартные задачи, искать новые способы действий, самостоятельно находить выход из критических ситуаций, прогнозировать последствия и нести ответственность за принятые решения. Все это требует профессиональной компетентности, выходящей за рамки привычных "репертуарных» действий и позволяющей справляться с ситуациями, когда проблемы до конца не ясны и не имеют готовых решений.

Вместе с тем неэффективное управление госслужащими на практике приводит к профессиональным деформациям и дисфункциям. Творческие способности специалистов налоговых органов находят выход и реализуются в других, часто коррупционных формах. Наблюдается несоответствие между необходимым уровнем компетентности и профессионализма госслужащих, с одной стороны, и существующим на практике - с другой. Его устранение - неотложная задача общегосударственного значения. Научное осмысление и решение проблемы управления профессиональным развитием госслужащих требует междисциплинарных знаний, использования различных концепций и подходов (концепции «нового государственного менеджмента», стратегического управления, социологии управления, социальной психологии и др.).

Предпосылками научного интереса к рассматриваемой проблеме послужили результаты исследования Д. Мак-Клелланда, который на обширном эмпирическом материале убедительно показал зависимость экономических успехов общества от выраженности у людей мотивации достижения [McClelland, 1961], а также работы других авторов, доказавших взаимосвязь экономических изменений в обществе с мотивацией, профессиональным развитием и компетентностью работников (см., напр.: [Равен, 2002; Хекхаузен, 2003, с. 375-380; Норт, 2010; Raven, 1997; 2012; Raven, Stephenson, 2001] и др.).

Так, лауреат Нобелевской премии по экономике Д. Норт указывал, что экономические изменения в обществе могут заканчиваться неудачей, потому что недооценивается фундаментальная роль ценностей и убеждений в поведении людей «Убеждения, которых придерживаются люди, определяют те выборы, которые они делают, что, в свою очередь, структурирует изменения в социальном ландшафте» [Норт, 2010, с. 42]. Создатель психологической теории компетентности Дж. Равен отмечал важную роль установок в эффективном государственном управлении: «Изменениям в нашем обществе не сопутствовали соответствующие перемены в общественном представлении о компетентности и об установках, которые требуются для эффективного управления» [Равен, 2002, с.5]. Он подчеркивал, что в формировании профессионалов ключевую, системообразующую роль играют ценности, мотивы, установки профессионала как личности, поскольку поведение человека в большей степени определяется его мотивацией, чем способностями. 
В процессе формирования и актуализации профессионализма госслужащих важны социальные факторы (мотивы и профессиональные установки), определяющие проявление инициативы, готовность к профессиональному обучению и развитию. В этой связи исследование социальных аспектов управления и профессиональной мотивации несомненно актуально и имеет практическую значимость, поскольку позволяет выявить субъективные мотивы профессионального развития госслужащих, степень их соответствия объективным потребностям общества в эффективном государственном управлении. Изучение и понимание социальных сил, изначально определяющих и контролирующих профессиональное поведение человека, должно лежать в основе управления профессиональным развитием госслужащих.

Эффективность и результативность деятельности государственных служб напрямую зависят от компетентности, профессионализма и профессиональной мотивации их руководителей. Важно, чтобы руководители были способны к профессиональному росту и заинтересованы в нем, а также в профессиональном развитии своих подчиненных. Профессионализм руководителей формируется под влиянием их профессиональных установок ${ }^{1}$, ценностных ориентаций и мотивации в профессиональных достижениях. Профессиональная мотивация является критическим фактором, определяющим профессионализм руководителей. Цель статьи - представить результаты эмпирического исследования профессиональных установок госслужащих - руководителей налоговых инспекций ФНС РФ.

Статья состоит из четырех разделов. В первом разделе представлен краткий обзор теоретико-методологических концепций и подходов к исследованию. Второй - раскрывает гипотезы и методы исследования. В третьем - дано описание проведенного исследования профессиональных установок руководителей ФНС РФ. Четвертый раздел включает обсуждение полученных результатов. В заключении отражены основные выводы и результаты, а также рекомендации по их использованию в практике управления профессиональным развитием государственных служащих ФНС РФ.

\section{МЕТОДОЛОГИЯ ИССЛЕДОВАНИЯ}

В течение двух последних десятилетий шло активное формирование концепции «нового государственного менеджмента» (New Public Management - NPM), которая сегодня востребована в процессах реформирования государственной службы [Баранов, 2012]. Теоретические дискуссии и подходы к осмыслению этой концепции нашли отражение в работах [Худ, Питерс, 2012; Kaboolian, 1998; Boyne,

\footnotetext{
1 Профессиональные установки человека - стремление овладеть профессией, получить специальную подготовку, добиться в ней успеха, определенного социального статуса и др. Профессиональные установки действуют на основе мотивации достижения, выступая в качестве иерархически более высокого уровня, чем профессиональные намерения и профессиональные решения (см.: http://enc-dic.com/word/p/Professionalne-ustanovki-cheloveka-118682.html).
} 
2002; Behn, 1995], а результаты эмпирических исследований по выявлению отличий менеджмента в бизнес-структурах и государственных организациях, эффектов от внедрения новых методов и подходов к государственному управлению обобщены в [Фобс, Линн, 2012]. Анализ международного опыта проведения реформ государственного управления дан в работах [Литвинцева, 2003; Мэннинг, Парисон, 2003].

В 1990-е гг. призыв NPM к внедрению методов менеджмента в сфере государственного управления привел к зарождению концепции «мотивации государственной службы» (Public Service Motivation - PSM). Идея PSM, впервые выдвинутая Дж. Пери и Л.Вайзом [Perry, Wise, 1990], получила свое развитие в их последующих работах (см., напр.: [Perry, 1996; 1997; 2000; Vandenabeele, 2007; Perry, Hondeghem, 2008a] и др.). Данная концепция играет важную роль в понимании мотивов и побуждений людей, выбирающих госслужбу, несмотря на экономические выгоды работы в бизнесе. Она фокусирует внимание на «мотивах и деятельности людей в общественном секторе, которые побуждают их делать добро другим и формировать благосостояние общества» [Perry, Hondeghem, 2008b, p. 3]. PSM изучает мотивы выбора работниками госслужбы и предлагает модель, которая концептуально ассоциируется с шестью измерениями: привлекательность формирования государственной политики, приверженность общественному интересу, гражданской обязанности, социальной справедливости, самопожертвованию и состраданию [Perry, 1996]. Однако вопросы измерения в PSM по-прежнему остаются актуальными для научного сообщества [Kim, 2009].

В настоящее время отмечается стремительный рост числа публикаций по PSM, что свидетельствует о важности данной проблематики. Критические обзоры исследований по PSM [Wright, 2001; Perry, Hondeghem, Wise, 2010; Bozeman, Xuhong, 2015; Ritz, Brewer, Neumann, 2016] охватывают широкий спектр рассматриваемых вопросов [Brewer, Selden, Facer, 2000]. Среди наиболее активно обсуждаемых - повышение эффективности работы [Alonso, Lewis, 2001; Kim, 2005; 2009; Gailmard, 2010], мотивация труда сотрудников [Bright, 2005; 2008; 2009; Buelens, Van den Broeck, 2007; Anderfuhren-Biget, et al., 2010], применение практик управления персоналом в госслужбе [Gould-Williams, 2003; Kim, 2010; Giauque, Anderfuhren-Biget, Varone, 2013], мотивация введения инноваций [Fernandez, Pitts, 2011], гендерные аспекты мотивации госслужащих [DeHart-Davis, Marlowe, Pandey, 2006] и др. Однако в зарубежных исследованиях по PSM работы по выявлению профессиональных установок госслужащих не представлены. Наиболее близкой к рассматриваемой тематике является статья [Hammer, 2000], которая не связана непосредственно с PSM.

Российские ученые и исследователи начали заниматься проблемами профессионализма госслужащих сравнительно недавно. Отдельные вопросы по этой тематике нашли отражение, например, в [Мальцев, 1997; Атаманчук, Матирко, 2001; Литвинцева, 2003; Калачева, Мальцев, Тихонина, 2004; Обухова, 2006; Сейтмухаметова, 2011]. Профессиональная среда государственных и муниципальных служащих на 
основе социокультурной концепции управления рассматривается в [Профессиональная культура..., 2007].

Вопросам управления профессиональным развитием госслужащих ФНС РФ посвящен ряд исследований (см., напр.: [Рогова, 2008; Стрекалова, Семенов, Рогова, 2014; Стрекалова, Рогова, 2015] и др.). Незначительное число публикаций отчасти объясняется закрытостью самого объекта (ФНС РФ), отсутствием доступа к его социальным контекстам. Проведенное исследование профессиональной деятельности госслужащих налоговых органов выявило ряд особенностей, обусловленных высоким уровнем ответственности и формированием общественной оценки результатов выполнения ими профильных функций, а также существующие проблемы в управлении и профессиональной среде налоговой службы. Было установлено влияние профессиональной среды на поведение госслужащих, развитие профессиональных деформаций или деструкций (авторитарность, доминантность, поведенческий трансфер, профессиональная агрессия, профессиональный догматизм, сверхконтроль) и других негативных явлений в управлении госслужбой (бюрократизм, волокита, несогласованность действий внутри организации, непрофессионализм) [Стрекалова, Семенов, Рогова, 2014, с. 24-25].

Профессиональное развитие кадров целесообразно рассматривать как «процесс качественного изменения профессиональных компетенций и накопления профессионального опыта, обеспечивающий профессиональную готовность и способность сотрудников к успешному осуществлению своей профессиональной деятельности» [Стрекалова, Рогова, 2015, с.31]. Социологический подход в исследовании управления профессиональным развитием госслужащих позволяет концентрировать внимание на социальных аспектах управленческой деятельности, мотивах, профессиональных установках и интересах людей. Будучи вполне самостоятельными, активными участниками процесса управления, госслужащие выстраивают свои алгоритмы социального взаимодействия, устанавливают собственные цели и приоритеты, с которыми необходимо считаться. Социологический подход (базирующийся на социологии управления) к анализу ФНС РФ позволяет учитывать ее специфику как социального института, координирующего социальное управление налоговыми правоотношениями в обществе [Стрекалова, Рогова, 2015, с. 13-17].

Важность изучения установок подчеркивал нобелевский лауреат Д.Норт: «Мы должны иметь не только четкое понимание структуры представлений и убеждений, служащей фундаментом для существующих институтов, но и тех пределов, в рамках которых система представлений поддается изменениям, позволяющим создание более производительных институтов» [Норт, 2010, с. 235]. Дж. Равен в своих исследованиях отмечал, что знания, навыки и умения, лежащие в основе исполнительской функции профессиональной деятельности руководителя, приобретаются и актуализируются только при личностном принятии и осознании значимости соответствующих целей, что определяет формирование инициативы, готовности к профессиональному обучению и развитию. Способность 
к эффективному управлению (на уровне организации и общества) требует от менеджеров таких качеств, как «предрасположенность к оценке и учету социальных факторов, которые существенно влияют на возможности организации». Согласно Дж. Равену, «взгляды на действительное и желаемое положение дел заметно влияют на реальную деятельность людей на всех уровнях управления организацией и обществом» [Равен, 2002, с. 21]. Однако практика показывает, что не все руководители изъявляют желание и готовность создавать в подчиненном им коллективе атмосферу, способствующую профессиональному развитию, инновациям и энтузиазму. В частности, Дж. Клемп, М. Магер и Л. Спенсер отмечали, что «именно предрасположенность к этим действиям и отличает эффективное руководство от неэффективного» ([Klemp, Munger, Spencer, 1977]; цит. по: [Равен, 2002, с. 27]).

Один из возможных способов эмпирического исследования профессиональной мотивации руководителей - выявление структуры и типов профессиональных установок путем тестирования и анализа высказываний руководителей о том, что для них важно и значимо в профессиональной деятельности. Настоящая статья направлена на изучение профессиональной мотивации госслужащих, выявление профессиональных установок руководителей налоговых инспекций.

\section{ГИПОТЕЗЫ И МЕТОДЫ ИССЛЕДОВАНИЯ}

Базовым для осуществления исследования стало предположение о том, что профессиональные установки руководителей оказывают существенное влияние на их деятельность, определяют предрасположенность и готовность к профессиональному развитию. В работе американского социального психолога Д. Майерса отмечается, что «установки и поступки подпитывают друг друга... иногда мы отстаиваем то, во что верим; но верно и то, что верим в то, что отстаиваем» [Майерс, 1999, с. 162-163]. В этой связи в настоящей статье поставлена задача провести эмпирическое исследование и выявить структуру, основные типы профессиональных установок руководителей (начальников налоговых инспекций) ФНС РФ.

Согласно Е.С. Миньковой, «в налоговых инспекциях доминирует авторитарный стиль руководства». Сами руководители налоговых инспекций признаются, что им «гораздо легче использовать приказной тон, не вызывающий возражений, чем общаться демократично» [Минькова, 2006, с. 70]. Диагностическое исследование профессиональной деятельности и профессиональной среды работников налоговых органов выявило наличие профессиональных деструкций и деформаций. Авторитарность как проявление жесткой вертикали власти, неумение и нежелание делегировать властные полномочия, строгая дисциплина, бюрократизм, волокита, сверхконтроль, требование неукоснительного соблюдения подчиненными должностных инструкций отмечаются у части работников налоговых органов, занимающих руководящие посты. Руководители авторитарного типа в большей мере склонны использовать на практике тактику наказания подчинен- 
ных, нежели анализировать их профессиональные ошибки. Наличие ярко выраженного уровня страха у подчиненных, опасений перед наказанием за допущенные ошибки свидетельствуют о преобладании авторитарного стиля управления [Стрекалова, Рогова, 2015, с. 42-43].

В рамках данного исследования были сформулированы две гипотезы.

Гипотеза 1. В структуре профессиональных установок руководителей (начальников налоговых инспекиий) превалируют профессиональные установки на карьерный рост, исполнительский характер труда.

Гипотеза 2. Руководители-женщины в большей степени ориентированы на профессионально-квалификаиионное развитие и творческий характер труда, чем руководители-мужчины.

Для проверки первой гипотезы и выявления профессиональных установок руководителей налоговых инспекций были использованы метод формализованного опроса и методика, предложенная Т.Г.Калачевой [Профессиональная культура..., 2007 , с.168-178]. Как представляется, метод формализованного опроса является единственно возможным для проведения исследований среди этой категории работников, поскольку применение других методов (включенного наблюдения, этнографического) затруднено в силу «закрытости» объекта исследования, отсутствия доступа к его социальным контекстам.

Выбор методики Т.Г. Калачевой обусловлен ее релевантностью, сфокусированностью на диагностике профессиональных установок государственных и муниципальных служащих. Она включает в себя тест Work и нацелена на выявление профессиональных установок государственных гражданских служащих. Тест Work дает возможность определить направленность установок государственных служащих на тип профессионального развития, что может служить основой для планирования профессионального и служебного развития кадров, целенаправленной мотивации профессиональной деятельности, планирования кадрового резерва.

В методике выделены два основных типа установок на профессиональное развитие: на должностное (карьерное) и профессионально-квалификационное. В ней также рассматриваются два типа установок по характеру профессиональной деятельности: творческий и исполнительский. Учитывая неодинаковую степень выраженности тех или иных установок у респондентов, а также их различные сочетания между собой, можно получить разные типы установок на профессиональную деятельность и профессиональное развитие государственных служащих.

Двумерная модель профессиональных установок представлена на рисунке. Ось ординат характеризует тип установок на профессиональное развитие (карьерное или профессионально-квалификационное), ось абсцисс - тип установок на характер профессиональной деятельности (творчество или исполнительство). Четыре квадранта модели характеризуются различными типологическими установками на характер профессиональной деятельности и тип профессионализма. 


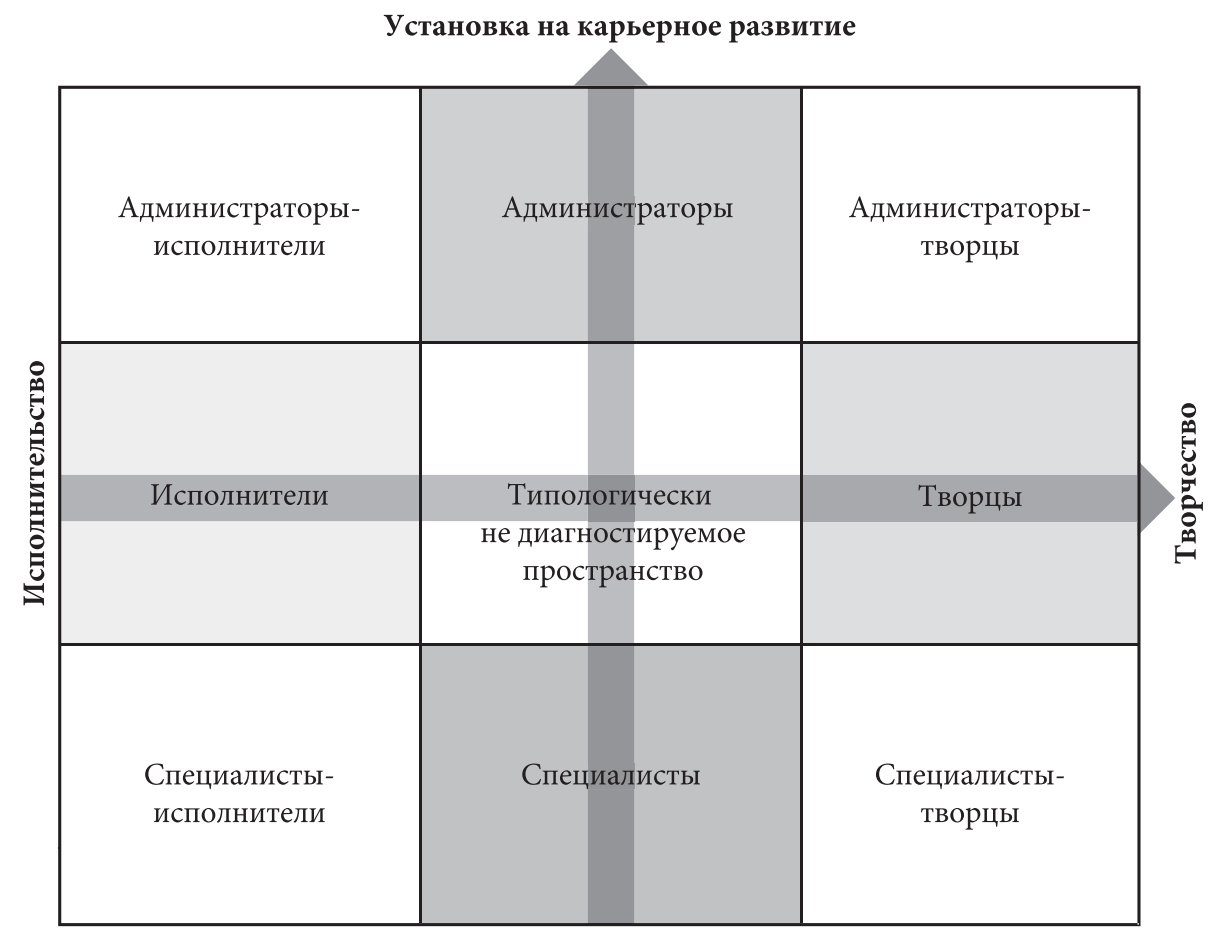

Установка на профессионально-квалификационное развитие

Рисунок. Модель профессиональных установок работников И с т о ч н и к: [Профессиональная культура..., 2007, с. 177].

В качестве инструмента для сбора данных использован тест Work ${ }^{2}$, состоящий из 84 пар суждений, отражающих ценности, связанные с работой. Респонденты должны были ответить на вопрос: «Что для Вас является самым важным в работе?» По каждой из пар высказываний им предстояло выбрать наиболее важное в сравнении с другим предложенным. Например, первая пара представлена следующими суждениями: «Занять высокую должность, сделать карьеру» и «Проявлять в работе творчество, инициативу». Обработка результатов теста Work проводилась в соответствии с указанным в методике алгоритмом. Полученные результаты заносились в двумерную модель профессиональных установок.

Выбранная методика позволяет исследователю решать две задачи, касающиеся установок работников в отношении типа профессионального развития: типологическую и индивидуально-диагностическую. Решение типологической задачи дает возможность классифицировать работников в плоскости ориентаций на тип профессионального развития и характер трудовой деятельности, а также

${ }^{2}$ Использованная методика, включающая содержание теста Work, алгоритм обработки его peзультатов и описание основных типов профессиональных установок государственных служащих, представлена в [Профессиональная культура..., 2007, с. 168-178]. 
выявить структуру их профессиональных установок. Индивидуально-диагностическая задача реализуется с целью индивидуальной диагностики и позволяет выявить индивидуальную принадлежность работника к определенному типу профессиональных установок (направленности) профессионального развития. Выполнение этой задачи может осуществляться как на этапе массового обследования, так и при индивидуальной диагностике.

\section{ОБЩАЯ ХАРАКТЕРИСТИКА ИССЛЕДОВАНИЯ И ЕГО РЕЗУЛЬТАТЫ}

Исследование профессиональных установок руководителей налоговых органов (начальников инспекций ФНС РФ) проводилось на базе Приволжского института повышения квалификации ФНС России (ранее - Центра подготовки персонала ФНС России, г. Нижний Новгород) в два этапа: в 2009 и в 2013 гг. В опросе 2009 г. приняли участие 50 человек, а в 2013 г. - 40 человек. В общей сложности опросом было охвачено 90 руководителей - начальников инспекций ФНС РФ из разных регионов России, которые проходили обучение по программам повышения квалификации. Доля женщин-руководителей, участвовавших в опросе, составила 68 \% от общего числа респондентов, и соответственно, 32 \% это доля руководителей-мужчин.

Предложенный респондентам тест Work заполнялся ими анонимно, поскольку соблюдение анонимности является важным фактором, позволяющим обеспечить получение ответов, отражающих действительное мнение респондентов, а не их представление о том, какие ответы хотело бы видеть их вышестоящее руководство. Данную выборку можно считать репрезентативной, она охватывает $9 \%$ от генеральной совокупности руководителей межрегиональных, городских, межрайонных и районных налоговых инспекций Российской Федерации.

Проверка второй гипотезы осуществлялась с использованием корреляционного анализа и критерия X-квадрат. Для проведения расчетов применена программа SPSS.

Результаты проверки гипотезы 1. Решение типологической задачи с целью выявления структуры профессиональных установок руководителей - начальников налоговых инспекций привело к следующим результатам (табл. 1).

Итак, в 2009 г. начальники налоговых инспекций в подавляющем большинстве (2/3 из числа опрошенных) имели установку на профессионально-квалификационное развитие (70\% респондентов) и творческий характер труда (66\%). Только $14 \%$ из общего числа опрошенных респондентов были ориентированы на карьерное продвижение в должности и $18 \%$ - на исполнительский характер труда. Респонденты, попавшие в типологически не диагностируемую область (16\%), имели смешанные установки (на тип профессионального развития и на характер профессиональной деятельности).

Сравнительный анализ показывает, что в 2013 г. структура распределения профессиональных установок руководителей налоговых инспекций в целом 
Таблица 1. Распределение профессиональных установок руководителей начальников налоговых инспекций

\begin{tabular}{|c|c|c|c|c|}
\hline \multirow[b]{2}{*}{$\begin{array}{c}\text { Профессиональные } \\
\text { установки }\end{array}$} & \multicolumn{2}{|c|}{2009 г. } & \multicolumn{2}{|c|}{2013 г. } \\
\hline & $\begin{array}{c}\text { Количество } \\
\text { респондентов }\end{array}$ & $\begin{array}{c}\text { Доля } \\
\text { опрошенных, } \\
\%\end{array}$ & $\begin{array}{c}\text { Количество } \\
\text { респондентов }\end{array}$ & $\begin{array}{c}\text { Доля } \\
\text { опрошенных, } \\
\%\end{array}$ \\
\hline \multicolumn{5}{|c|}{ По типу профессионального развития } \\
\hline $\begin{array}{l}\text { Профессионально- } \\
\text { квалификационное развитие }\end{array}$ & 35 & 70 & 28 & 70 \\
\hline Карьерное развитие & 7 & 14 & 4 & 10 \\
\hline $\begin{array}{l}\text { Типологически } \\
\text { не характеризуемые }\end{array}$ & 8 & 16 & 8 & 20 \\
\hline \multicolumn{5}{|c|}{ По характеру профессиональной деятельности } \\
\hline Творчество & 33 & 66 & 31 & 77,5 \\
\hline Исполнительство & 9 & 18 & 1 & 2,5 \\
\hline $\begin{array}{l}\text { Типологически } \\
\text { не характеризуемые }\end{array}$ & 8 & 16 & 8 & 20 \\
\hline
\end{tabular}

сохранила свои черты: 2/3 из числа опрошенных (70 \%) по-прежнему ориентированы на профессионально-квалификационное развитие и $3 / 4-$ на творческий характер труда (77,5\%). При этом доля руководителей, предпочитающих использовать творческий подход к решению профессиональных задач, значительно выросла (на 11,5 пр. п.), а доля руководителей, ориентированных на исполнительский характер деятельности, существенно снизилась (на 15,5 пр. п.). На карьерный рост в выбранной профессиональной сфере в 2013 г. были ориентированы только $10 \%$ из общего числа респондентов по сравнению с $14 \%$ в 2009 г. Респонденты, показавшие смешанные установки как на тип профессионального развития, так и на характер профессиональной деятельности и попавшие в типологически не диагностируемую область, составляли $16 \%$ в 2009 г. и $20 \%$ - в 2013 г.

Итак, выдвинутая гипотеза о том, что в структуре профессиональных установок руководителей (начальников налоговых инспекций) превалируют установки на карьерный рост и исполнительский характер труда, в целом не подтвердилась.

Реализация индивидуально-диагностической задачи исследования по данной методике позволила выявить структуру распределения руководителей налоговых инспекций по типу профессиональных установок (табл. 2). В методике Т. Г. Калачевой были выделены следующие типы установок работников: «администраторы», «администраторы-творцы», «творцы», «специалисты-творцы», «специалисты», «специалисты-исполнители», «исполнители», «администраторы-исполнители» и «типологически не характеризуемые». Следует отметить, что указанные типы профессиональных установок не следует расценивать как хорошие или плохие. Они просто разные, но эти различия необходимо учитывать в управлении профессиональным развитием кадров, в процессе реализации кадровой политики. 
Социальные аспекты управления профессиональным развитием...

Таблица 2. Распределение руководителей - начальников налоговых инспекций по типу профессиональных установок

\begin{tabular}{|c|c|c|c|c|}
\hline \multirow[b]{2}{*}{$\begin{array}{c}\text { Тип профессиональных } \\
\text { установок }\end{array}$} & \multicolumn{2}{|c|}{2009 г. } & \multicolumn{2}{|c|}{2013 г. } \\
\hline & $\begin{array}{c}\text { Количество } \\
\text { респондентов }\end{array}$ & $\begin{array}{c}\text { Доля } \\
\text { опрошенных, } \\
\%\end{array}$ & $\begin{array}{c}\text { Количество } \\
\text { респондентов }\end{array}$ & $\begin{array}{c}\text { Доля } \\
\text { опрошенных, } \\
\%\end{array}$ \\
\hline Специалисты-творцы & 20 & 40 & 20 & 50 \\
\hline Специалисты & 9 & 18 & 2 & 5 \\
\hline Творцы & 7 & 14 & 7 & 17,5 \\
\hline Администраторы-творцы & 2 & 4 & 1 & 2,5 \\
\hline Администраторы-исполнители & 2 & 4 & 0 & 0 \\
\hline Специалисты-исполнители & 2 & 4 & 0 & 0 \\
\hline Исполнители & 0 & 0 & 0 & 0 \\
\hline Администраторы & 0 & 0 & 2 & 5 \\
\hline $\begin{array}{l}\text { Типологически не } \\
\text { характеризуемые }\end{array}$ & 8 & 16 & 8 & 20 \\
\hline Итого & 50 & 100 & 40 & 100 \\
\hline
\end{tabular}

Как видно из табл. 2, в рассматриваемом пространстве установок в 2009 и 2013 гг. преобладает тип «специалисты-творцы». Для этого типа работников характерны высокий уровень нацеленности на профессионально-квалификационное развитие и творческий характер труда. Им свойственна внутренняя мотивация труда, установка на профессиональную активность и лидерство. Их отличают стремление к развитию и самореализации в выбранной сфере деятельности, потребность в получении дополнительных профессиональных знаний.

В 2013 г. по сравнению с 2009 г. более чем втрое снизилась доля руководителей типа «специалисты». Эти работники характеризуются высоким уровнем установок на профессиональное развитие (профессионализм специалиста) и смешанным (не ярко выраженным) типом установок на характер профессиональной деятельности. Этой группе руководителей присуще стремление к достаточно активной профессиональной деятельности, протекающей в относительно комфортных условиях.

Руководителям с профессиональными установками (тип «творцы»), на долю которых приходилось 14\% в 2009 г. и 17,5\% - в 2013 г., свойственна стратегическая направленность на творчество, внутреннюю мотивацию труда, профессиональную активность и лидерство. Вместе с тем они характеризуются не ярко выраженной ориентацией на профессионализм специалиста или профессионализм администратора. Их можно рассматривать в качестве резерва как для группы «специалистов-творцов», так и для «администраторов-творцов».

Таким образом, почти $3 / 4$ из общего числа опрошенных руководителей $(72 \%$ в 2009 г. и 72,5\% - в 2013 г.) относятся к трем основным типам: «специалистытворцы», «творцы», «специалисты». Остальные типы («специалисты-исполнители», «администраторы-исполнители», «администраторы-творцы») имеют невысокую долю в общей численности опрошенных респондентов. В рамках данного 
исследования среди начальников инспекций в 2009 г. не было выявлено типов «исполнители» и «администраторы», а в 2013 г. - типа «исполнители». Далее представлена краткая характеристика работников с указанными типами установок [Профессиональная культура..., 2007, с. 175-176].

«Администраторы-творцы» демонстрируют ярко выраженный тип карьерных установок в сочетании с ориентацией на творчество, профессиональную активность и профессиональное лидерство. По сути, это тип администратора-предпринимателя, открытого новациям и риску. Для «администраторов-исполнителей» характерны установки на тип административного, карьерного развития. Предпочтение отдается комфортным условиям труда, а не профессиональной активности, творчеству и личностному лидерству в коллективе. В оптимальном варианте это руководители исполнительского типа, а в случае максимальных значений характеристик - администраторы карьеристского типа. У «специалистов-исполнителей» высокий уровень ориентации на профессиональную самореализацию как специалиста сочетается со стремлением к исполнительским функциям, с установками на комфортность условий профессиональной деятельности. Для работников с типом профессиональных установок «исполнителя» характерна не ярко выраженная ориентация на тип развития специалиста или администратора. Главное для них - комфортность условий профессиональной деятельности. Данная группа является кадровым резервом для становления либо «специалиста-исполнителя», либо «администратора-исполнителя», что зависит от того, в каком направлении будут развиваться установки, связанные с профессиональной деятельностью (на профессиональное развитие или карьеру). «Администраторы» - тип служащих, которым присущи установки на административную карьеру, социальный престиж. По фактору профессиональной мотивации они характеризуются не ярко выраженными установками на творчество, профессиональную активность и лидерство или на комфортность условий профессиональной деятельности. Это тип взвешенного администратора, предпочитающего работать хотя и творчески, но в устойчивой ситуации, не предполагающей принятия рискованных решений. Респонденты, оказавшиеся в пространстве «типологически не характеризуемые», имеют смешанные установки в отношении как профессионального развития, так и характера деятельности (творческого или исполнительского).

Результаты проверки гипотезы 2. Как отмечалось, в 2009 г. среди 50 опрошенных респондентов $68 \%$ составляли женщины и $32 \%$ - мужчины. Гендерный анализ профессиональных установок руководителей - начальников налоговых инспекций показал, что среди них преобладают руководители-женщины (тип «специалисты-творцы»), которые в большей степени ориентированы на профессионально-квалификационное развитие, творческий характер труда и в меньшей - на карьерное продвижение (табл. 3).

Первичный анализ полученных данных позволил предположить, что существует определенная зависимость между переменными гендера и типом профессиональной установки. Результаты проверки этой гипотезы представлены в табл. 4. 
Социальные аспекты управления профессиональным развитием...

Таблица 3. Распределение руководителей налоговых инспекций по типу профессиональных установок: гендерный аспект, 2009 г.

\begin{tabular}{|l|c|c|c|c|c|c|}
\hline \multirow{2}{*}{$\begin{array}{c}\text { Тип профессиональных } \\
\text { установок }\end{array}$} & \multicolumn{2}{|c|}{ Мужчины } & \multicolumn{2}{c|}{ Женщины } & \multicolumn{2}{c|}{ Всего } \\
\cline { 2 - 7 } & $\begin{array}{c}\text { Количество } \\
\text { респондентов }\end{array}$ & $\%$ & $\begin{array}{c}\text { Количество } \\
\text { респондентов }\end{array}$ & $\begin{array}{c}\text { Количество } \\
\text { респондентов }\end{array}$ & $\%$ \\
\hline Специалисты-творцы & 3 & 19 & 17 & 50 & 20 & 40 \\
\hline Специалисты & 4 & 25 & 5 & 14,7 & 9 & 18 \\
\hline Творцы & 2 & 12,5 & 5 & 14,7 & 7 & 14 \\
\hline Администраторы-творцы & 2 & 12,5 & 0 & 0 & 2 & 4 \\
\hline $\begin{array}{l}\text { Администраторы- } \\
\text { исполнители }\end{array}$ & 2 & 12,5 & 0 & 0 & 2 & 4 \\
\hline Специалисты-исполнители & 1 & 6 & 1 & 3 & 2 & 4 \\
\hline Исполнители & 0 & 0 & 0 & 0 & 0 & 0 \\
\hline Администраторы & 0 & 0 & 0 & 0 & 0 & 0 \\
\hline $\begin{array}{l}\text { Типологически не } \\
\text { характеризуемые }\end{array}$ & 2 & 12,5 & 6 & 17,6 & 8 & 16 \\
\hline Итого & 16 & 100 & 34 & 100 & 50 & 100 \\
\hline
\end{tabular}

Анализ интенсивности частот показывает, что наибольшее расхождение в них наблюдается по типу «специалисты-творцы» у руководителей-женщин (наблюдаемая частота составила 17; ожидаемая - 14,3). Наблюдаемая частота у руководителей-мужчин (тип «специалисты-творцы») меньше ожидаемой (3 и 5,7 соответственно).

Анализ отклонений наблюдаемых и ожидаемых частот ${ }^{3}$ делает еще более заметной противоположную тенденцию в самооценке профессиональных установок у мужчин и у женщин. Так, для типов «специалисты-творцы», «специалистыисполнители», «творцы» наблюдаемая частота у женщин выше, чем ожидаемая (17 и 14,7; 1 и 0,7; 5 и 4,8 соответственно), тогда как для типов «администраторисполнитель», «администратор-творец», «специалист» она ниже (0 и 1,4; 0 и 1,4; 5 и 6,1 соответственно). В отношении мужчин видна противоположная тенденция. Для типов «специалисты-творцы», «специалисты-исполнители», «творцы» наблюдаемая частота ниже, чем ожидаемая ( 3 и 5,7; 1 и 1,3; 2 и 2,2 соответственно), тогда как для «администратора-исполнителя», «администратора-творца», «специалиста» она выше ( 2 и 0,6; 2 и 0,6; 4 и 2,9 соответственно). Выдвинутая нами гипотеза о том, что женщины считают себя в большей степени ориентированными на профессионально-квалификационное развитие и творческий характер труда, чем руководители-мужчины, подтверждается.

3 Анализ значений ожидаемых частот позволяет исследовать зависимость между переменными (гендер, тип профессиональной установки). Две переменные считаются взаимно-независимыми, если наблюдаемые частоты совпадают с ожидаемыми. 
Таблица 4. Таблица сопряженности: тип профессиональных установок и гендер респондентов

\begin{tabular}{|c|c|c|c|c|}
\hline \multirow{2}{*}{$\begin{array}{c}\text { Тип профессиональных } \\
\text { установок }\end{array}$} & \multirow{2}{*}{$\begin{array}{c}\text { Частота/ } \\
\text { Нормированный остаток }\end{array}$} & \multicolumn{2}{|c|}{ Гендер респондента } & \multirow{2}{*}{ Всего } \\
\hline & & Мужчины & Женщины & \\
\hline \multirow{3}{*}{ Специалисты } & Наблюдаемая & 4 & 5 & 9 \\
\hline & Ожидаемая & 2,9 & 6,1 & 9,0 \\
\hline & Нормированный остаток & 0,7 & $-0,5$ & - \\
\hline \multirow{3}{*}{ Специалисты-творцы } & Наблюдаемая & 3 & 17 & 20 \\
\hline & Ожидаемая & 5,7 & 14,3 & 20,0 \\
\hline & Нормированный остаток & $-1,0$ & 0,7 & - \\
\hline \multirow{3}{*}{ Творцы } & Наблюдаемая & 2 & 5 & 7 \\
\hline & Ожидаемая & 2,2 & 4,8 & 7,0 \\
\hline & Нормированный остаток & $-0,2$ & 0,1 & - \\
\hline \multirow{3}{*}{ Специалисты-исполнители } & Наблюдаемая & 1 & 1 & 2 \\
\hline & Ожидаемая & 1,3 & 0,7 & 2,0 \\
\hline & Нормированный остаток & $-0,6$ & 0,4 & - \\
\hline \multirow{3}{*}{$\begin{array}{l}\text { Администраторы- } \\
\text { исполнители }\end{array}$} & Наблюдаемая & 2 & 0 & 2 \\
\hline & Ожидаемая & 0,6 & 1,4 & 2,0 \\
\hline & Нормированный остаток & 1,7 & $-1,2$ & - \\
\hline \multirow{3}{*}{ Администраторы-творцы } & Наблюдаемая & 2 & 0 & 2 \\
\hline & Ожидаемая & 0,6 & 1,4 & 2,0 \\
\hline & Нормированный остаток & 1,7 & $-1,2$ & - \\
\hline \multirow{3}{*}{$\begin{array}{l}\text { Типологически не } \\
\text { характеризуемые }\end{array}$} & Наблюдаемая & 2 & 6 & 8 \\
\hline & Ожидаемая & 2,6 & 5,4 & 8,0 \\
\hline & Нормированный остаток & $-0,4$ & 0,2 & - \\
\hline
\end{tabular}

Анализ нормированных остатков предоставляет еще одну возможность выявления зависимости между переменными (тип установки, гендер). Нормированный остаток рассчитывался по формуле

$$
O=\frac{f^{o}-f^{e}}{\sqrt{f^{e}}},
$$

где $O-$ нормированный остаток; $f^{o}-$ наблюдаемая частота; $f^{e}-$ ожидаемая частота.

Нормированные остатки являются показателем того, насколько сильно наблюдаемые и ожидаемые частоты отклоняются друг от друга. Считается, что существует значимое расхождение между наблюдаемой и ожидаемой частотой, если нормированный остаток больше или равен 2. Однако эти правила применимы, когда ожидаемая частота не меньше 5. 
Критерий $X$-квадрат рассчитывался по формуле Пирсона:

$$
X^{2}=\sum_{i, j} \frac{\left(f^{o}-f^{e}\right)^{2}}{f^{e}}
$$

где $i$ - номер строки, $j$ - номер столбца ячейки в таблице сопряженности.

Ячейки таблицы сопряженности с более высоким нормированным остатком вносят более весомый вклад в численное значение критерия $X$-квадрат и, следовательно, в значимый результат. Предельные значения нормированных остатков и уровня значимости (по критерию $X$-квадрат) оценивались и принимались в расчет в соответствии с данными табл. 5.

Таблица 5. Нормированные остатки и уровни значимости

\begin{tabular}{|c|l|}
\hline Нормированный остаток & \multicolumn{1}{|c|}{ Уровень значимости } \\
\hline$\geq 2,0$ & $p<0,05-$ значимо \\
\hline$\geq 2,6$ & $p<0,01-$ очень значимо \\
\hline$\geq 3,3$ & $p<0,001-$ максимально значимо \\
\hline
\end{tabular}

И с т о ч н и к: [Бююль, Цефель, 2002, с. 191].

Профессиональная установка (типа «специалисты-творцы») у руководителей-женщин встречается в 5 раз чаще, чем у руководителей-мужчин, однако эту зависимость нельзя признать значимой, поскольку величины нормированных остатков ниже 2 (табл. 4). Таким образом, гипотеза 2 о том, что у женщин преобладает установка на тип профессионально-квалификационного развития и творческий характер труда, в целом подтвердилась, однако данная зависимость не является значимой.

\section{ОБСУЖДЕНИЕ ПОЛУЧЕННЫХ РЕЗУЛЬТАТОВ}

Анализ полученных результатов показал, что руководители налоговых инспекций в определенной степени удовлетворены своим должностным статусом и не стремятся к карьерному продвижению. Это обстоятельство может быть обусловлено рядом причин:

1) изменением трудовых ценностей и приоритетов в мотивах профессиональной деятельности: с течением времени более приоритетными стали получение удовлетворенности от самой профессиональной деятельности, творчества и менее - стремление продвинуться по карьерной лестнице;

2) неудовлетворенностью уровнем материального вознаграждения, который не компенсирует увеличение напряженности труда и возрастающую меру ответственности; 
3) влиянием чисто субъективных факторов, таких как приверженность профессиональной деятельности специалиста, с которой начиналась карьера руководителя, а также нехватка управленческих компетенций, порождающая неуверенность в своих силах на более высоких должностях;

4) отсутствием желания делать свою карьеру в условиях реструктуризации $Ф Н С$ РФ, в том числе проведения мероприятий по сокращению численности персонала, ротации кадров ${ }^{4}$.

Исследование также выявило, что руководители-женщины в меньшей степени ориентированы на карьерное продвижение, чем руководители-мужчины. Такой результат может быть вызван влиянием социально-культурных стереотипов в обществе и других, субъективных факторов, что удалось выяснить в ходе проведенного с ними собеседования. Например, в ответах женщин - руководителей инспекций на вопросы, связанные с возможностью должностного роста или профессионально-квалификационного развития, преобладал выбор второго варианта, что объясняется такими факторами, как:

1) укоренение в российском обществе социокультурного стереотипа о том, что за женщиной признается право на профессиональную деятельность без претензий на карьеру;

2) женщины, занимающие главный руководящий пост в налоговых инспекциях, полагают, что уже достигли наивысшей точки своего должностного роста и их вполне устраивает достигнутый социальный статус;

3) низкая мотивация к получению вышестоящей должности (например, должности руководителя управления) связана как с меньшей вероятностью ее получения (число позиций ограничено), так и с большей ответственностью на данном посту, наличием высокой конкуренции со стороны руководителей-мужчин, стремлением высшего руководства ФНС РФ сохранить в налоговых органах специалистов-мужчин;

4) заниженная самооценка руководителей-женщин, отсутствие внутренней установки на получение более высокой руководящей должности;

5) отсутствие необходимого уровня развития деловых навыков, лидерских качеств, инициативы, искусства эффективной самопрезентации и др.

Безусловно, полученные результаты исследования следует рассматривать в контексте имеющихся ограничений. Во-первых, они характеризуют выборку в целом, однако могут не подтверждаться применительно к конкретному индивиду. В идеале необходимо анализировать индивидуальную структуру профессиональных установок и особенности каждого отдельного работника, а затем использовать эти результаты для планирования его профессионального развития, повышения эффективности деятельности.

${ }^{4}$ Следует отметить, что в 2012 г. в ходе реорганизации налоговой службы проводилась существенная ротация кадров, а именно: вновь были назначены 23 руководителя и 65 заместителей руководителей управлений, 135 начальников налоговых инспекций. 
Во-вторых, использованная методика, позволяя выявить структуру и типы профессиональной мотивации, дает информацию об установках личности на основе самооценок своих возможностей, однако не характеризует индивидуальные способности респондентов, для оценки которых целесообразно дополнительно использовать другие методики. Тем не менее ее можно рекомендовать для планирования профессионального развития конкретных госслужащих (руководителей, специалистов) в профессиональном или административном направлении, для принятия управленческих решений о продвижении в должности. Полученные результаты должны быть дополнены использованием более тонких психологических или социально-психологических методик.

В-третьих, для актуализации данных требуется систематическое повторение исследований по предложенной методике на больших выборках, так как мотивы респондентов могут с течением времени меняться.

Таким образом, проведенное исследование позволило установить, что формирование и развитие структуры профессиональных установок государственных служащих - руководителей налоговых инспекций происходит под влиянием как внешних (социокультурные стереотипы в обществе, действующие в налоговой службе системы материального стимулирования, мотивации профессионального развития), так и внутренних (субъективных) факторов. В совокупности они обусловливают функциональную стереотипность поведения руководителей, ориентацию на сохранение достигнутого уровня профессионального развития, карьерного роста, а не на достижение нового. Все это подтверждает необходимость целенаправленного управленческого воздействия на профессиональное развитие госслужащих, разработки эффективных систем планирования кадрового резерва, мотивации профессионального и карьерного роста.

\section{ЗАКЛЮЧЕНИЕ}

В ходе проведенного исследования были сделаны определенные выводы и получены результаты, которые могут представлять интерес для созданного в 2015 г. Совета ФНС РФ по профессиональному развитию федеральных государственных гражданских служащих налоговых органов.

Цель настоящего исследования заключалась в том, чтобы на основе изучения концептуальных и методологических основ и подходов к анализу профессиональной мотивации государственных служащих выявить структуру и провести анализ профессиональных установок руководителей - начальников налоговых инспекций ФНС РФ, выработать рекомендации по управлению профессиональным развитием госслужащих. Было выявлено, что в структуре профессиональных установок руководителей налоговых инспекций преобладает нацеленность на профессионально-квалификационное развитие и творческий характер труда. Гипотеза о том, что в структуре их профессиональных установок превалируют установки на карьерный рост и исполнительский характер труда, не подтвердилась. 
Гендерный анализ показал, что среди руководителей налоговых инспекций преобладают руководители-женщины. Выборочные данные не дают оснований отвергнуть гипотезу о том, что руководители-женщины в большей степени ориентированы на профессионально-квалификационное развитие и творческий характер труда, чем руководители-мужчины, однако эта зависимость не является значимой.

Полученные результаты в совокупности с проектом Программы профессионального развития кадров ФНС РФ и плана мероприятий по ее реализации, предложенных в работе [Стрекалова, Рогова, 2015, с. 81-85, 119-134], имеют практическую значимость для стратегического кадрового планирования, реализации Концепции кадровой политики ФНС РФ. Они могут быть использованы руководством кадровых служб ФНС РФ для решения таких задач, как:

1) формирование типологической структуры кадров (руководителей и специалистов), позволяющей рассматривать особенности каждого отдельного работника, учитывать индивидуальную структуру его профессиональных установок, с целью планирования адресной работы по профессиональному развитию государственных служащих в профессиональном или карьерном направлениях, повышения эффективности той профессиональной деятельности, которая им лучше всего подходит;

2) разработка планов профессиональной подготовки кадров, отбора госслужащих для переподготовки или повышения квалификации, прохождения стажировок;

3) определение потребностей в обучении госслужащих, разработке программ обучения с учетом выявленных образовательных потребностей специалистов и руководителей, проблем их профессиональной среды (необходимости формирования навыков эффективного управления, повышения эффективности работы в командах и др.);

4) целенаправленное создание кадрового резерва на замещение руководящих должностей, принятие решений по продвижению госслужащих по карьерной лестнице, проведение вертикальной и горизонтальной ротации кадров;

5) комплексная оценка текущего состояния кадрового потенциала, проведение аттестации сотрудников, адресная оценка работы госслужащих и разработка рекомендаций с учетом выявленных типов их ориентаций на профессиональное развитие;

6) разработка и реализация мотивационного механизма управления профессиональным развитием государственных служащих налоговых органов.

Теоретический вклад исследования состоит в развитии концепции PSM (вопросов профессиональной мотивации, управления профессиональным развитием госслужащих), тестировании методики определения профессиональных установок государственных гражданских служащих. Кроме того, его новизна связана с выбором самого предмета и объекта анализа - мотивации профессионального развития госслужащих ФНС РФ, которые рассматриваются с позиций NPM, PSM, социологии управления. 
Социальные аспекты управления профессиональным развитием...

Перспективные направления дальнейших исследований могут быть связаны с разработкой единой системы управления профессиональным развитием кадров ФНС, ее мотивационного механизма, системы мониторинга и диагностики профессиональной среды с целью эффективного управления ФНС РФ.

\section{Литература}

Атаманчук С. Г., Матирко В. И. Государственная служба: кадровый потенциал. М.: Дело, 2001. Баранов И. Н. Новый государственный менеджмент // Российский журнал менеджмента. 2012. T. 10, № 1. С. 51-64.

Бююль А., Цефель П. SPSS: искусство обработки информации. Анализ статистических данных и восстановление скрытых закономерностей. М.: ДиаСофт, 2002.

Калачева Т., Мальцеев В., Тихонина С. Профессиональная среда государственной гражданской службы. Н. Новгород: ВВАГС, 2004.

Литвинцева Е. А. Государственная служба в зарубежных странах. М.: РАГС, 2003.

Майерс Д. Социальная психология. СПб.: Питер, 1999.

Мальцев В. А. Социологический подход к анализу профессионализма государственных служащих. М.: РАГС, 1997.

Минькова Е.С. Роль личностных особенностей налогового инспектора в развитии синдрома эмоционального сгорания // Дополнительное профессиональное образование специалистов налоговых органов: достижения, проблемы, тенденции: тезисы докладов. Н. Новгород: Стимул-СТ, 2006. С. 67-71.

Мэннинг Н., Парисон Н. Реформа государственного управления: международный опыт. М.: Весь мир, 2003.

Норт Д. Понимание процесса экономических изменений. М.: Издат. дом НИУ ВШЭ, 2010.

Об утверждении Концепции кадровой политики Федеральной налоговой службы. Приказ ФНС РФ от 11.07.2011 г. № ММВ-7-4/436.

Обухова Л. А. Профессионализация кадрового обеспечения органов государственного управления. Абакан: Изд-во ХГУ им. Н.Ф. Катанова, 2006.

О создании Совета ФНС России по профессиональному развитию федеральных государственных гражданских служащих налоговых органов. Приказ ФНС РФ от 18.09. 2015 г. № CA-7-3/363

Профессиональная культура государственных и муниципальных служащих: социокультурная концепция. Н. Новгород: Изд-во Волго-Вятской академии гос. службы, 2007.

Равен Дж. Компетентность в современном обществе: выявление, развитие и реализация. М.: Когито-центр, 2002.

Рогова Г. И. Влияние мотивации специалиста на результативность труда и уровень профессионального развития // Вестн. С.-Петерб. ун-та МВД России. 2008. № 4 (40). С. 229-232.

Сейтмухаметова М.В.Управление мотивацией профессионального развития муниципальных служащих: автореф. дис. ... канд. социол. наук. М., 2011.

Стрекалова Н.Д., Рогова Г.И. Управление профессиональным развитием государственных гражданских служащих налоговых органов. СПб.: Астерион, 2015.

Стрекалова Н. Д., Семенов В. А., Рогова Г.И. Профессиональная среда как фактор профессионального развития государственных служащих налоговой службы // Управленческое консультирование. 2014. № 2 (62). С. 15-26.

Фобс М., Линн Л. Как государственный менеджмент влияет на эффективность исполнительных органов власти? // Российский журнал менеджмента. 2012. Т.10, № 1. С.85116.

Хекхаузен Х. Мотивация и деятельность. 2-е изд. СПб.: Питер; М.: Смысл, 2003. 
Худ К., Питерс Г. Средний возраст нового государственного менеджмента: время парадоксов? // Российский журнал менеджмента. 2012. Т. 10, № 1. С. 65-84.

Alonso P., Lewi G. Public Service Motivation and Job Performance: Evidence from the Federal Sector // American Review of Public Administration. 2001. Vol.31, N 4. P.363-380.

Anderfuhren-Biget S., Varone F., Giauque D., Ritz A. Motivating Employees of the Public Sector: Does Public Service Motivation Matter? // International Public Management Journal. 2010. Vol.13, N 3. P. 213-246.

Behn R. The Big Questions of Public Management // Public Administration Review. 1995. Vol.55, N 4. P.313-324.

Boyne G. Public and Private Management: What's the Difference? // Journal of Management Studies. 2002. Vol.39, N 1. P. 97-122.

Bozeman B., Xuhong S. Public Service Motivation Concepts and Theory: A Critique // Public Administration Review. 2015. Vol.75, N 5. P.700-710.

Brewer G., Selden S., Facer R. Individual Conceptions of Public Service Motivation // Public Administration Review. 2000. Vol.60, N 3. P. 254-264.

Bright L. Public Employees with High Levels of Public Service Motivation. Who Are They, Where Are They, and What Do They Want? // Review of Public Personnel Administration. 2005. Vol.25, N 2. P. 138-154.

Bright L. Does Public Service Motivation Really Make a Difference on the Job Satisfaction and Turnover Intentions of Public Employees? // American Review of Public Personnel Administration. 2008. Vol.38, N 2. P. 149-166.

Bright L. Why Do Public Employees Desire Intrinsic Nonmonetary Opportunities? // Public Personnel Management. 2009. Vol.38, N 3. P. 15-37.

Buelens M., Van den Broeck H. An Analysis of Differences in Work Motivation between Public and Private Sector Organizations // Public Administration Review. 2007. Vol.67, N 1. P.65-74.

DeHart-Davis L., Marlowe J., Pandey S. Gender Dimensions of Public Service Motivation // Public Administration Review. 2006. Vol.66, N 6. P. 873-887.

Fernandez S., Pitts D. Understanding Employee Motivation to Innovate: Evidence from Front Line Employees in United States Federal Agencies // Australian Journal of Public Administration. 2011.Vol. 70, N 2. P. 202-222.

Gailmard S. Politics, Principal-Agent Problems, and Public Service // International Public Management Journal. 2010. Vol. 13, N 1. P.35-45.

Giauque D., Anderfuhren-Biget S., Varone F. HRM Practices, Intrinsic Organizational Performance in the Public Sector // Public Personnel Management. 2013. Vol.42, N 2. P. 123-150.

Gould-Williams J. The Importance of HR Practices and Workplace Trust in Achieving Superior Performance: A Study of Public-Sector Organizations // International Journal of Human Resource Management. 2003. Vol. 14, N 1. P. 28-54.

Hammer D. Professional Attitudes and Behaviors: The "A's and B's" of Professionalism // American Journal of Pharmaceutical Education. 2000. Vol. 64, N 1. P. 455-464.

Kaboolian L. The New Public Management: Challenging the Boundaries of the Management vs. Administration Debate // Public Administration Review. 1998. Vol.58, N 3. P. 189-193.

Kim J. Strategic Human Resource Practices: Introducing Alternatives for Organizational Performance Improvement in the Public Sector // Public Administration Review. 2010. Vol. 70, N 1. P.38-49.

Kim S. Individual-Level Factors and Organizational Performance in Government Organizations // Journal of Public Administration Research and Theory. 2005. Vol.15, N 2. P. 245-261.

Kim S. Revising Perry' Measurement Scale of Public Service Motivation // American Review of Public Administration. 2009. Vol.39, N 2. P. 149-163.

Klemp G. O., Munger M. T., Spencer L. M. An Analysis of Leadership and Management Competencies of Commissioned and Non-Commissioned Naval Officers in the Pacific and Atlantic Fleets. Boston: McBer, 1977. 
McClelland D. The Achieving Society. Princeton, NJ: Van Nostrand, 1961.

Perry J. Measuring Public Service Motivation: An Assessment of Construct Reability and Validity // Journal of Public Administration Research and Theory. 1996. Vol.6, N 1. P.5-22.

Perry J. Antecedents of Public Service Motivation // Journal of Public Administration Research and Theory. 1997. Vol. 7, N 2. P. 181-197.

Perry J. Bringing Society in: Toward a Theory of Public-Service Motivation // Journal of Public Administration Research and Theory. 2000. Vol. 10, N 2. P. 471-488.

Motivation in Public Management: The Call of Public Service / eds J.Perry, A. Hondeghem. Oxford: Oxford University Press, 2008a.

Perry J., Hondeghem A. Building Theory and Empirical Evidence about Public Service Motivation // International Public Management Journal. 2008b. Vol 11, N 1. P.3-12.

Perry J., Wise L. The Motivational Bases of Public Service // Public Administration Review. 1990. Vol. 50, N 3. P. 367-373.

Perry J., Hondeghem A., Wise L. Revisiting the Motivational Bases of Public Service: Twenty Years of Research and an Agenda for the Future // Public Administration Review. 2010. Vol.70, N 5. P. 681-690.

Raven J. Competence in Modern Society: Its Identification, Development and Release. Unionville, New York: Royal Fireworks Press, 1997.

Raven J. Competence, Education, Professional Development, Psychology, and Socio-Cybernetics // Continuing Professional Development and Lifelong Learning: Issues, Impacts, and Outcomes / ed. by G. J. Neimeyer. Hauppauge, New York: Nova Science Publishers, Inc, 2012. P. 277-315.

Raven J., Stephenson J. Competence in the Learning Society. New York: Peter Lang, 2001.

Ritz A., Brewer G., Neumann O. Public Service Motivation: A Systematic Literature Review and Outlook // Public Administration Revie. 2016. Vol.76, N 3. P. 414-426.

Vandenabeele W. Toward a Public Administration Theory of Public Service Motivation: An Institutional Approach // Public Management Review. 2007. Vol.9, N 4. P. 545-556.

Wright B. Public-Sector Work Motivation: A Review of the Current Literature and a Revised Conceptual Model // Journal of Public Administration Research and Theory. 2001. Vol.11, N 4. P. 559-586.

Для цитирования: Стрекалова Н.Д., Рогова Г.И. Социальные аспекты управления профессиональным развитием государственных служащих Федеральной налоговой службы России: результаты эмпирического исследования // Вестник СПбГУ. Серия 8. Менеджмент. Вып. 3. C. $82-106$. DOI: $10.21638 / 11701 /$ spbu08.2016.304

\section{References}

Atamanchuk S. G., Matirko V.I. Gosudarstvennaia sluzhba: kadrovyi potentsial [Public Service: Human Resources]. Moscow, Delo Publ., 2001. (In Russian)

Baranov I.N. Novyi gosudarstvennyi menedzhment [New Public Management: An Evolution of Theory and Implementation]. Rossiiskii zhurnal menedzhmenta, 2012, vol. 10, no. 1, pp. 51-64. (In Russian)

Biuiul' A., Tsefel' P. SPSS. Iskusstvo obrabotki informatsii, analiz statisticheskikh dannykh i vosstanovlenie skrytykh zakonomernostei [SPSS. The Art of Information Processing, Analysis of Statistical Data and Restore Hidden Patterns]. Moscow, DiaSoft Publ., 2002. (In Russian)

Kalacheva T., Mal'tsev V., Tikhonina S. Professional'naia sreda gosudarstvennoi grazhdanskoi sluzhby [The Professional Environment of the Civil Service]. Nizhny Novgorod, VVAGS Publ., 2004. (In Russian)

Litvintseva E. A. Gosudarstvennaia sluzhba v zarubezhnykh stranakh [Public Service in Foreign Countries]. Moscow, RAGS Publ., 2003. (In Russian) 
Mal'tsev V.A.Sotsiologicheskii podkhod $k$ analizu professionalizma gosudarstvennykh sluzhashchikh [The Sociological Approach to the Analysis of Professionalism of Civil Servants]. Moscow, RAGS Publ., 1997. (In Russian)

Min'kova E.S. Rol' lichnostnykh osobennostei nalogovogo inspektora $\mathrm{v}$ razvitii sindroma emotsional'nogo sgoraniia [The Role of the Personal Characteristics of a Tax Inspector in the Development of Syndrome of Emotional Combustion]. Dopolnitel'noe professional'noe obrazovanie spetsialistov nalogovykh organov: dostizheniia, problemy, tendentsii: tezisy dokladov. Nizhny Novgorod, Stimul-ST Publ., 2006, pp. 67-71. (In Russian)

Menning N. Parison N. Reforma gosudarstvennogo upravleniia: mezhdunarodnyi opyt [Public Administration Reform: International Experience]. Moscow, Ves' mir Publ., 2003. (In Russian)

Nort D. Ponimanie protsessa ekonomicheskikh izmenenii [Understanding the Process of Economic Change]. Moscow, Publishing House NIU VShE, 2010. (In Russian)

Ob utverzhdenii Kontseptsii kadrovoi politiki Federal'noi nalogovoi sluzhby [On Approval of the Concept of the Federal Tax Service Personnel Policy]. Prikaz FNS RF ot 11.07.2011 g. № MMV-7-4/436. (In Russian)

Obukhova L. A. Professionalizatsiia kadrovogo obespecheniia organov gosudarstvennogo upravleniia [The Professionalization of Staffing Government]. Abakan, KhGU im. N. F. Katanova Publ., 2006. (In Russian)

O sozdanii Soveta FNS Rossii po professional'nomu razvitiiu federal'nykh gosudarstvennykh grazhdanskikh sluzhashchikh nalogovykh organov [On the Creation of Russian Federal Tax Service of the Council on the Professional Development of Federal Civil Servants of the Tax Authorities]. Prikaz FNS RF ot 18.09. 2015 g. № SA-7-3/363. (In Russian)

Professional'naia kul'tura gosudarstvennykh i munitsipal'nykh sluzhashchikh: sotsiokul'turnaia kontseptsiia [Professional Culture of Public and Municipal Employees: The Socio-Cultural Concept]. Nizhny Novgorod, Volgl-Viatskoi akademii gos. sluzhby Publ., 2007. (In Russian)

Raven Dzh. Kompetentnost'v sovremennom obshchestve: vyiavlenie, razvitie i realizatsiia [Competence in Modern Society: Its Identification, Development and Release]. Moscow, Kogito-tsentr Publ., 2002. (In Russian)

Rogova G.I. Vliianie motivatsii spetsialista na rezul'tativnost' truda i uroven' professional'nogo razvitiia [Influence of Motivation of a Specialist in the Work Performance and Level of Professional Development]. Vestnik of Saint Petersburgskogo universiteta MVD Rossii, 2008, no. 4 (40), pp. 229 232. (In Russian)

Seitmukhametova M. V. Upravleniemotivatsiei professional'nogo razvitiia munitsipal'nykh sluzhashchikh. Avtoref. diss. kand. sotsiol. nauk [Management Motivation of Municipal Employees' Professional Development. Thesis of PhD]. Moscow, 2011. (In Russian)

Strekalova N.D., Rogova G. I. Upravlenie professional'nym razvitiem gosudarstvennykh grazhdanskikh sluzhashchikh nalogovykh organov [Management of Professional Development of Tax Service Civil Servants]. St. Petersburg, Asterion Publ., 2015. (In Russian)

Strekalova N.D., Semenov V.A., Rogova G.I. Professional'naia sreda kak faktor professional'nogo razvitiia gosudarstvennykh sluzhashchikh nalogovoi sluzhby [Professional Environment as a Factor of Professional Development of Tax Service Civil Servants]. Upravlencheskoe konsul'tirovanie, 2014, no. 2 (62), pp. 15-26. (In Russian)

Fobs M., Linn L. Kakgosudarstvennyi menedzhment vliiaet na effektivnost' ispolnitel'nykh organov vlasti? [How Does Public Management Affect Government Performance? Findings from International Research] Rossiiskii zhurnal menedzhmenta, 2012, vol. 10, no. 1, pp. 85-116. (In Russian)

Khekkhauzen Kh. Motivatsiia i deiatel'nost' [Motivation and Activities]. $2^{\text {nd }}$. ed. St. Petersburg: Piter Publ.; Moscow, Smysl Publ., 2003. (In Russian)

Khud K., Piters G. Srednii vozrast novogo gosudarstvennogo menedzhmenta: vremia paradoksov? [The Middle Aging of New Public Management: Into the Age of Paradox?] Rossiiskii zhurnal menedzhmenta, 2012, vol. 10, no. 1, pp. 65-84. (In Russian) 
Alonso P., Lewi G. Public Service Motivation and Job Performance: Evidence from the Federal Sector. American Review of Public Administration, 2001, vol. 31, no. 4, pp. 363-380.

Anderfuhren-Biget S., Varone F., Giauque D., Ritz A. Motivating Employees of the Public Sector: Does Public Service Motivation Matter? International Public Management Journal, 2010, vol. 13, no. 3, pp. 213-246.

Behn R. The Big Questions of Public Management. Public Administration Review, 1995, vol. 55, no. 4, pp. 313-324.

Boyne G. Public and Private Management: What's the Difference? Journal of Management Studies, 2002, vol. 39, no. 1, pp. 97-122.

Bozeman B., Xuhong S. Public Service Motivation Concepts and Theory: A Critique. Public Administration Review, 2015, vol. 75, no. 5, pp. 700-710.

Brewer G., Selden S., Facer R. Individual Conceptions of Public Service Motivation. Public Administration Review, 2000, vol. 60, no. 3, pp. 254-264.

Bright L. Public Employees with High Levels of Public Service Motivation. Who Are They, Where Are They, and What Do They Want? Review of Public Personnel Administration, 2005, vol. 25, no. 2, pp. 138-154.

Bright L. Does Public Service Motivation Really Make a Difference on the Job Satisfaction and Turnover Intentions of Public Employees? American Review of Public Personnel Administration, 2008, vol. 38, no. 2, pp. 149-166.

Bright L. Why Do Public Employees Desire Intrinsic Nonmonetary Opportunities? Public Personnel Management, 2009, vol. 38, no. 3, pp. 15-37.

Buelens M., Van den Broeck H. An Analysis of Differences in Work Motivation between Public and Private Sector Organizations. Public Administration Review, 2007, vol. 67, no. 1, pp. 65-74.

DeHart-Davis L., Marlowe J., Pandey S. Gender Dimensions of Public Service Motivation. Public Administration Review, 2006, vol. 66, no. 6, pp. 873-887.

Fernandez S., Pitts D. Understanding Employee Motivation to Innovate: Evidence from Front Line Employees in United States Federal Agencies. Australian Journal of Public Administration, 2011, vol. 70, no. 2, pp. 202-222.

Gailmard S. Politics, Principal-Agent Problems, and Public Service. International Public Management Journal. 2010, vol. 13, no. 1, pp. 35-45.

Giauque D., Anderfuhren-Biget S., Varone F. HRM Practices, Intrinsic Organizational Performance in the Public Sector. Public Personnel Management, 2013, vol. 42, no. 2, pp. 123-150.

Gould-Williams J. The Importance of HR Practices and Workplace Trust in Achieving Superior Performance: A Study of Public-Sector Organizations. International Journal of Human Resource Management, 2003, vol. 14, no. 1, pp. 28-54.

Hammer D. Professional Attitudes and Behaviors: The "A's and B's" of Professionalism. American Journal of Pharmaceutical Education, 2000, vol. 64, no. 1, pp. 455-464.

Kaboolian L. The New Public Management: Challenging the Boundaries of the Management vs. Administration Debate. Public Administration Review, 1998, vol. 58, no. 3, pp. 189-193.

Kim J. Strategic Human Resource Practices: Introducing Alternatives for Organizational Performance Improvement in the Public Sector. Public Administration Review, 2010, vol. 70, no. 1, pp. 38-49.

Kim S.Individual-Level Factors and Organizational Performance in Government Organizations. Journal of Public Administration Research and Theory, 2005, vol. 15, no. 2, pp. 245-261.

Kim S. Revising Perry' Measurement Scale of Public Service Motivation. American Review of Public Administration, 2009, vol. 39, no. 2, pp. 149-163.

Klemp G. O., Munger M.T., Spencer L. M. An Analysis of Leadership and Management Competencies of Commissioned and Non-Commissioned Naval Officers in the Pacific and Atlantic Fleets. Boston, McBer Publ., 1977.

McClelland D. The Achieving Society. Princeton, NJ, Van Nostrand Publ., 1961. 
Perry J. Measuring Public Service Motivation: An Assessment of Construct Reability and Validity. Journal of Public Administration Research and Theory, 1996, vol. 6, no. 1, pp. 5-22.

Perry J. Antecedents of Public Service Motivation. Journal of Public Administration Research and Theory, 1997, vol. 7, no. 2, pp. 181-197.

Perry J. Bringing Society in: Toward a Theory of Public-Service Motivation. Journal of Public Administration Research and Theory, 2000, vol. 10, no. 2, pp. 471-488.

Motivation in Public Management: The Call of Public Service. Eds J. Perry, A. Hondeghem. Oxford, Oxford University Press, 2008a.

Perry J., Hondeghem A. Building Theory and Empirical Evidence about Public Service Motivation. International Public Management Journal, 2008b, vol 11, no. 1, pp. 3-12.

Perry J., Wise L. The Motivational Bases of Public Service. Public Administration Review. 1990, vol. 50, no. 3, pp. 367-373.

Perry J., Hondeghem A., Wise L. Revisiting the Motivational Bases of Public Service: Twenty Years of Research and an Agenda for the Future. Public Administration Review, 2010, vol. 70, no. 5, pp. 681-690.

Raven J. Competence in Modern Society: Its Identification, Development and Release. Unionville, New York, Royal Fireworks Press, 1997.

Raven J. Competence, Education, Professional Development, Psychology, and Socio-Cybernetics. Continuing Professional Development and Lifelong Learning: Issues, Impacts, and Outcomes. Ed. by G. J. Neimeyer. Hauppauge, New York, Nova Science Publishers, Inc, 2012, pp. 277-315.

Raven J., Stephenson J. Competence in the Learning Society. New York, Peter Lang Publ., 2001.

Ritz A., Brewer G., Neumann O. Public Service Motivation: A Systematic Literature Review and Outlook. Public Administration Revie, 2016, vol.76, no. 3, pp. 414-426.

Vandenabeele W. Toward a Public Administration Theory of Public Service Motivation: An Institutional Approach. Public Management Review, 2007, vol. 9, no. 4, pp. 545-556.

Wright B. Public-Sector Work Motivation: A Review of the Current Literature and a Revised Conceptual Model. Journal of Public Administration Research and Theory, 2001, vol. 11, no. 4, pp. 559-586.

For citation: Strekalova N. D., Rogova G. I. Social Aspects of Professional Development Management of Russian Federal Tax Service Civil Servants: Results of Empirical Research. Vestnik SPbSU. Series 8. Management, 2016, issue 3, pp. 82-106. DOI: 10.21638/11701/spbu08.2016.304

Статья поступила в редакцию 17 ноября 2014 г.; принята к печати 22 июня 2016 г.

Контактная информация:

Стрекалова Наталья Дмитриевна - доктор экономических наук, профессор; nstrekalova@hse.ru

Рогова Галина Ивановна - кандидат социологических наук; rogova-gala@rambler.ru

Strekalova Natalia D. - Doctor of Economics, Professor; nstrekalova@hse.ru

Rogova Galina I. - PhD; rogova-gala@rambler.ru 